\title{
Direct Oral Anticoagulants in Nonvalvular Atrial Fibrillation: Practical Considerations on the Choice of Agent and Dosing
}

\author{
Dimitrios Farmakis ${ }^{\mathrm{a}}$ Periklis Davlouros ${ }^{\mathrm{b}}$ Gregory Giamouzis ${ }^{\mathrm{c}}$ \\ George Giannakoulas $^{d}$ Athanasios Pipilis ${ }^{e}$ Georgios Tsivgoulis ${ }^{f}$ \\ John Parissis ${ }^{a}$
}

a Department of Cardiology, Heart Failure Unit, Attikon University Hospital, National and Kapodistrian University of Athens, Athens, Greece; ${ }^{b}$ Department of Cardiology, Patras University Hospital, Patras, Greece; ${ }^{\mathrm{C}}$ Department of Cardiology, Larissa University Hospital, Larissa, Greece; ' First Department of Cardiology, AHEPA Hospital,

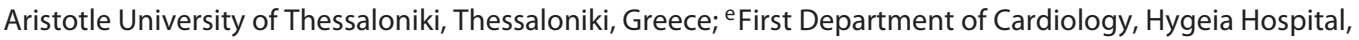
Athens, Greece; ${ }^{\mathrm{f}}$ Second Department of Neurology, Attikon University Hospital, National and Kapodistrian University of Athens, Athens, Greece

\section{Keywords}

Atrial fibrillation · New oral anticoagulants · Dabigatran ·

Rivaroxaban · Apixaban · Edoxaban

\begin{abstract}
Direct or new oral anticoagulants (NOACs), including the direct thrombin inhibitor dabigatran and the direct factor $\mathrm{Xa}$ inhibitors rivaroxaban, apixaban, and edoxaban, have recently revolutionized the field of antithrombotic therapy for stroke and systemic embolism prevention in nonvalvular atrial fibrillation (NVAF). Randomized controlled trials have shown that these agents have at least comparable efficacy with vitamin $\mathrm{K}$ antagonists along with superior safety, at least in what concerns intracranial hemorrhage. As a result, NOACs are indicated as first-line anticoagulation therapy for NVAF patients with at least one risk factor for stroke or systemic embolism. The rapid introduction, however, of NOACs
\end{abstract}

\section{KARGER}

(c) 2018 S. Karger AG, Basel

E-Mail karger@karger.com

www.karger.com/crd in a field dominated for decades by vitamin antagonists and the variety of agents and dosing schemes may create difficulties in decision making. In the present article, we attempt to determine a practical approach to the choice of agent and dose in different clinical scenarios by considering not only the results of seminal randomized trials and post hoc analyses but also data from real-world patient populations as well as the recently available possibility of rapid NOAC reversal.

(c) 2018 S. Karger AG, Basel

\section{Introduction}

The class of direct or new oral anticoagulants (NOACs) has recently revolutionized the field of antithrombotic therapy by providing a handful of novel agents with adequate efficacy, enhanced safety, and unparalleled usability for a spectrum of clinical indications, including stroke
Dimitrios Farmakis, MD, PhD, FESC 
Table 1. Seminal randomized controlled trials and key post hoc analyses on the efficacy and safety of NOACs for stroke and systemic embolism prevention in nonvalvular atrial fibrillation; OR or HRs and 95\% CI of NOACs versus warfarin

\begin{tabular}{|c|c|c|c|c|c|c|c|}
\hline & \multicolumn{2}{|l|}{ RE-LY ${ }^{1}$} & \multirow{2}{*}{$\begin{array}{l}\text { RE-LY } \\
\text { EU post-hoc analysis } \\
\text { dabigatran } \\
110 \mathrm{mg} / 150 \mathrm{BID}\end{array}$} & \multirow{2}{*}{$\begin{array}{l}\text { ARISTOTLE }^{3} \\
\text { apixaban } \\
2.5 / 5 \mathrm{mg} \mathrm{BID}\end{array}$} & \multirow{2}{*}{$\begin{array}{l}\text { ROCKET AF } \\
\text { rivaroxaban } \\
15 / 20 \mathrm{mg} \mathrm{OD}\end{array}$} & \multirow{2}{*}{$\begin{array}{l}\text { ROCKET AF } \\
\text { post-hoc analysis } \\
\text { Rivaroxaban } \\
15 / 20 \mathrm{mg} \text { OD }\end{array}$} & \multirow{2}{*}{$\begin{array}{l}\text { ENGAGE AF-TIMI } 48^{6} \\
\text { edoxaban } \\
30 / 60 \mathrm{mg} \text { OD }\end{array}$} \\
\hline & $\begin{array}{l}\text { dabigatran } \\
110 \mathrm{mg} \text { BID }\end{array}$ & $\begin{array}{l}\text { dabigatran } \\
150 \text { mg BID }\end{array}$ & & & & & \\
\hline Stroke/systemic embolism & $0.89(0.73-1.09)$ & $0.65(0.52-0.81)$ & $0.74(0.60-0.91)$ & $0.79(0.66-0.95)$ & $0.88(0.75-1.03)$ & & $0.87(0.73-1.04)$ \\
\hline Intracranial bleeding & $0.31(0.20-0.47)$ & $0.40(0.27-0.60)$ & $0.28(0.17-0.45)$ & $0.42(0.30-0.58)$ & $0.67(0.47-0.93)$ & & $0.47(0.34-0.63)$ \\
\hline Major bleeding & $0.80(0.69-0.93)$ & $0.94(0.82-1.08)$ & $0.85(0.73-0.98)$ & $0.69(0.60-0.80)$ & $1.04(0.90-1.20)$ & & $0.80(0.71-0.91)$ \\
\hline Gastrointestinal bleeding & $1.10(0.86-1.41)$ & $1.50(1.19-1.89)$ & $1.23(0.96-1.59)$ & $0.89(0.70-1.15)$ & & $1.42(1.22-1.66)^{*}$ & $1.23(1.02-1.50)$ \\
\hline Mortality & $0.91(0.80-1.03)$ & $0.88(0.77-1.00)$ & $0.86(0.75-0.98)$ & $0.89(0.80-0.99)$ & $0.85(0.70-1.02)$ & $1.66(1.34-2.05)^{+}$ & $0.92(0.83-1.01)$ \\
\hline
\end{tabular}

${ }^{1}$ Connolly et al. [1]; ${ }^{2}$ Lip et al. [2]; ${ }^{3}$ Granger et al. [3]; ${ }^{4}$ Patel et al. [4]; ${ }^{5}$ Sherwood et al. [11]; ${ }^{6}$ Giugliano et al. [5].

* Major or non-major clinical bleeding; ${ }^{+}$major bleeding.

NOACs, new oral anticoagulants; HRs, hazard ratios.

and systemic embolism prevention in nonvalvular atrial fibrillation (NVAF) and prevention and treatment of deep vein thrombosis and pulmonary embolism. In the field of NVAF, in particular, NOACs, including the direct thrombin inhibitor dabigatran and the direct factor $\mathrm{Xa}$ inhibitors rivaroxaban, apixaban, and edoxaban have shown at least comparable efficacy with vitamin $\mathrm{K}$ antagonists (VKAs) coupled with superior safety, at least in what concerns intracranial hemorrhage [1-5]. The seminal randomized controlled trials that provided the key evidence on the efficacy and safety of NOACs for stroke and systemic embolism prevention in NVAF compared to VKAs are summarized in Table 1. Given the results of these trials, guidelines currently recommend NOACs as first-line anticoagulation therapy for NVAF patients with one or more risk factors for stroke or systemic embolism [6].

With the introduction and the steadily increasing use of NOACs in a field that had been dominated by VKAs for several decades, a number of treatment algorithms have been developed and published to guide clinicians in choosing the right anticoagulant for the right patient with NVAF [7-10]. These algorithms are mainly based on evidence provided by clinical trials of NOACs and some of them are quite complicated and difficult to follow. In addition, agents that reverse rapidly the action of NOACs are becoming available and this development should also be taken under consideration. Therefore, there is a need for a practical guide for the use of NOACs in NVAF that would incorporate clinical trial data but also real-world evidence, take into consideration the possibility of rapid NOAC reversal, and provide a simple but not oversimplified approach to decision making in this demanding field of clinical medicine.

Direct Oral Anticoagulants in Nonvalvular Atrial Fibrillation

\section{Evidence on Key Efficacy and Safety Outcomes by Randomized Controlled Trials}

In terms of efficacy, all 4 NOACs have been found to be at least non-inferior to warfarin in preventing stroke and systemic embolism $[1-5,11]$, while dabigatran $150 \mathrm{mg}$ twice daily (BID) and apixaban have been proved superior to warfarin for this very endpoint. In terms of safety, all 4 NOACs have been associated with a lower risk of intracranial hemorrhage compared with warfarin. In what concerns the risk of major bleeding, NOACs have proved at least comparable to warfarin, while dabigatran $110 \mathrm{mg} \mathrm{BID}$, apixaban, and edoxaban have been associated with a lower risk. In gastrointestinal bleeding, dabigatran $110 \mathrm{mg}$ BID and apixaban have been associated with a similar risk, edoxaban $30 \mathrm{mg}$ once daily (OD) with a lower risk and dabigatran $150 \mathrm{mg}$ BID, rivaroxaban and edoxaban $60 \mathrm{mg}$ OD with an increased risk when compared to warfarin. Finally, in terms of mortality, there was no difference between warfarin and either rivaroxaban or edoxaban, while data from apixaban, as well as pooled data from dabigatran were indicative of reduced mortality $[2,3]$. The outcome of randomized controlled trials comparing NOACs with VKAs in terms of key efficacy and safety endpoints is summarized in Table 2.

The documented safety of NOACs have further been enhanced by the recent development of reversal agents that provide rapid reversal of anticoagulation action either in case of emergent invasive procedures or in the event of life-threatening or uncontrolled bleeding. More specifically, idaricizumab, a humanized monoclonal antibody specific for dabigatran, neutralizes the anticoagulant effect of dabigatran within minutes and has been ap- 
Table 2. Key efficacy and safety outcomes of NOAC randomized controlled trials compared with warfarin

\begin{tabular}{|c|c|c|c|c|c|c|}
\hline & & \multirow{2}{*}{$\begin{array}{l}\text { Efficacy } \\
\text { stroke and systemic } \\
\text { embolism }\end{array}$} & \multicolumn{3}{|l|}{ Safety } & \multirow[t]{2}{*}{ Mortality } \\
\hline & & & major bleeding & $\begin{array}{l}\text { gastrointestinal } \\
\text { bleeding }\end{array}$ & $\begin{array}{l}\text { intracranial } \\
\text { hemorrhage }\end{array}$ & \\
\hline Dabigatran 110 mg BID & & Non-inferior & Decreased & Comparable & Decreased & Comparable \\
\hline Dabigatran 150 mg BID & & Superior & Comparable & Increased & Decreased & Comparable \\
\hline Dabigatran pooled EU & & Superior & Decreased & Comparable & Decreased & Decreased \\
\hline Edoxaban 30 mg OD & & Non-inferior & Decreased & Decreased & Decreased & Comparable \\
\hline Edoxaban 60 mg OD & & Non-inferior & Decreased & Increased & Decreased & Comparable \\
\hline
\end{tabular}

proved for clinical use in Europe and the United States since 2015 [12]. The second reversal agent that has been developed is andexanet alpha, a recombinant modified factor Xa that acts as a decoy by competitively binding with all factor Xa inhibitors. Clinical evidence is encouraging, but the agent has not yet been approved for clinical use [13].

It should be stressed that patients with valvular $\mathrm{AF}$, defined as hemodynamically relevant valve disease (RE-LY) or moderate to severe mitral stenosis (ARISTOTLE, ROCKET AF and ENGAGE AF) were excluded from the aforementioned trials $[1,3-5]$. Regarding valve prostheses, patients with any prosthetic valves were excluded from RE-LY (dabigatran) and ROCKET AF (rivaroxaban), while bioprosthetic valves were allowed in ARISTOTLE (apixaban) and ENGAGE AF-TIMI 48 (edoxaban) according to study protocols [1, 3-5]. In addition, patients having undergone annuloplasty, with or without prosthetic ring, commissurotomy, and/or valvuloplasty were permitted in ROCKET AF and those with any valve repair were also allowed in ENGAGE AF $[4,5]$.

Regarding the concomitant use of antiplatelet agents, low-dose aspirin monotherapy was generally allowed in all seminal NOAC trails, while patients in need of higher aspirin dose ( $>100 \mathrm{mg}$ [ROCKET AF] or $>165 \mathrm{mg}$ [ARISTOTLE]) or dual antiplatelet therapy had been excluded $[1,3-5]$.

\section{Real-World Comparative Evidence for NOACs}

The major randomized trials that established the efficacy and safety of NOACs compared these agents with warfarin as the previous standard of care. Therefore, evidence on head-to-head comparison of different NOACs is limited and has been derived mainly by observational studies or registries. Although these studies bear several inherent limitations and therefore their results should be interpreted with caution, they provide real-world data that may be more representative of patients treated in everyday clinical practice, particularly when based on large cohorts.

In a recent meta-analysis of 17 observational studies comparing rivaroxaban, dabigatran, and warfarin, rivaroxaban was as efficacious as dabigatran for the prevention of stroke or systemic embolism (hazard ratio [HR] 1.02; 95\% CI 0.91-1.13), but it was associated with an increased risk of major bleeding (HR 1.38; 95\% CI 1.27-1.49), gastrointestinal bleeding (HR 1.33; 95\% CI 1.18-1.48), and all-cause mortality (HR 1.23; 95\% CI 1.12-1.33) when compared with dabigatran [14]. However, there was no difference between the 2 agents in the risk of acute myocardial infarction or intracranial hemorrhage.

A propensity score-weighed prospective analysis of nationwide data from 3 Danish registries on 61,678 patients with NVAF who were new users of either a NOAC (dabigatran, apixaban, or rivaroxaban) at standard doses or warfarin, showed that dabigatran and apixaban were associated with a significantly lower risk of any bleeding (intracranial, major gastrointestinal, or traumatic intracranial) and major bleeding compared with rivaroxaban or warfarin at 1 year (adjusted HR for major bleeding, dabigatran vs. warfarin, 0.58 [95\% CI $0.47-0.71]$, apixaban vs. warfarin, 0.61 [0.49-0.75], rivaroxaban vs. warfarin, 1.06 [0.91-1.23]) [15]. In addition, dabigatran and apixaban were associated with a lower risk of all-cause death at 1 year (adjusted HR, dabigatran vs. warfarin, 0.63 [0.48-0.82], apixaban vs. warfarin, 0.65 [0.56-0.75], rivaroxaban vs. warfarin, $0.92[0.82-1.03])$.

An American Food and Drug Administration study analyzed retrospectively data from 118, 891 elderly Medicare beneficiaries aged $\geq 65$ years with NVAF treated with 
either dabigatran $150 \mathrm{mg}$ BID or rivaroxaban $20 \mathrm{mg}$ [16]. The study reported that compared with rivaroxaban, dabigatran was associated with a significantly lower risk of major extracranial bleeding (HR 1.48 [1.32-1.67]), major gastrointestinal bleeding (HR 1.40 [1.23-1.59]), and intracranial hemorrhage (HR 1.65 [1.20-2.26]) after an average follow-up of 4 months. However, there was no difference between the 2 agents in thromboembolic stroke (HR 0.81 [0.65-1.01]) or all-cause death (HR 1.15 [1.00$1.32])$.

\section{Specific Anticoagulants for Specific Patient Profiles}

The selection of anticoagulation agents may be individualized based on patient characteristics and the results of the aforementioned randomized controlled trials and large observational studies. More specifically, in NVAF patients with labile international normalized ratio (INR) values or in those who were unable to check INR regularly, one of the 4 NOACs should be prescribed. In patients with incident stroke or thromboembolic event while on VKA therapy, NOACs with superior efficacy than VKAs in preventing ischemic and hemorrhagic stroke should be selected, namely, dabigatran $150 \mathrm{mg}$ BID or apixaban. In patients with severe renal dysfunction with estimated glomerular filtration rate (eGFR) values $<15 \mathrm{~mL} / \mathrm{min} / 1.73 \mathrm{~m}^{2}$ or on hemodialysis, the only currently indicated anticoagulants are VKAs. Patients with moderate to severe renal function impairment (eGFR $15-30 \mathrm{~mL} / \mathrm{min} / 1.73 \mathrm{~m}^{2}$ ) may be treated with reduced doses of rivaroxaban (15 mg OD), apixaban ( $2.5 \mathrm{mg}$ BID) or edoxaban (30 mg OD), while patients with moderate renal dysfunction (eGFR $30-50 \mathrm{~mL} / \mathrm{min} / 1.73 \mathrm{~m}^{2}$ ) may be treated with dabigatran $110 \mathrm{mg}$ BID (or $150 \mathrm{mg}$ BID if no other risk factors for bleeding exist), apixaban (5 mg BID), or reduced doses of rivaroxaban (15 mg OD) or edoxaban (30 mg OD).

Although the use of NOACs has not been assessed in randomized trials comparing patients with and without bleeding history or with high and low-risk of bleeding, according to available evidence from the previously described randomized trials and observational studies, patients with a history or a high risk of gastrointestinal bleeding should rather be treated with dabigatran 110 mg BID, apixaban, or edoxaban. The same may further apply to patients an increased hemorrhagic risk, as defined by a HASBLED score of 3 or higher. When there are additional safety concerns, it should be taken under consideration that dabigatran is for the time being the

Direct Oral Anticoagulants in Nonvalvular Atrial Fibrillation only agent with an approved reversal agent. In elderly patients aged $>80$ years, the most suitable agents are dabigatran $110 \mathrm{mg}$ BID, rivaroxaban, or apixaban. Patients with recent stroke and nasogastric tube due to dysphagia should be treated with rivaroxaban ( 15 or 20 $\mathrm{mg}$ based on creatinine clearance), since direct administration of dabigatran or apixaban to the nasograstic tube is not safe. Finally, drug-to-drug interactions should be considered in patients receiving other essential medications, as for example, in cancer patients with atrial fibrillation [17]. More specifically, VKA should be used cautiously in the presence of a long list of agents that either increase or decrease INR. In the case of NOACs, drug-to-drug interactions are numerically less and mainly concerns agents that affect cytochrome CYP3A4 or P-glycoprotein. The most suitable NOACs for specific patient profiles are summarized in Table 3.

\section{A Practical Approach to Dosing}

In clinical practice, dosing of NOACs seems to be rather frequent and may have important clinical sequelae. One out of 8 patients with NVAF treated with target-specific NOACs in a practice-based registry received doses other than those recommended in Food and Drug Administration-approved labels [18]. Apixaban was the most common NOAC that was under-dosed. Patients given doses that were higher than recommended exhibited greater all-cause mortality, and those receiving lower than recommended doses had more cardiovascular hospitalizations than those prescribed the recommended doses of these agents.

Two different dosing regimens of dabigatran were tested in the seminal RE-LY trial [1]. The $150 \mathrm{mg}$ BID regimen was proved to be more efficacious than warfarin in preventing stroke and systemic embolism, with a similar risk of major bleeding, while the $110 \mathrm{mg}$ BID regimen had a similar efficacy with warfarin but with enhanced safety regarding major bleeding. In patients requiring oral anticoagulation, as defined by a $\mathrm{CHA}_{2} \mathrm{DS}_{2} \mathrm{VASc}$ score of 1 or higher and no contraindication because of impaired renal function (eGFR $<30 \mathrm{~mL} / \mathrm{min} / 1.73 \mathrm{~m}^{2}$ ), the choice between the 2 dosing regimens can initially be guided by age and concomitant medications. Patients who are older than 80 years or treated with concomitant antiplatelet agents or verapamil should receive $110 \mathrm{mg}$ BID. In contrast, patients who are younger than 75 years and not treated with the above medications should receive $150 \mathrm{mg}$ BID. Finally, in patients aged $75-80$ years, 
Table 3. Recommended NOACs for specific patient profiles

\begin{tabular}{|c|c|}
\hline $\begin{array}{l}\text { Labile INR, inability to check INR } \\
\text { regularly }\end{array}$ & $\begin{array}{l}\text { Dabigatran } \\
\text { Rivaroxaban } \\
\text { Apixaban } \\
\text { Edoxaban }\end{array}$ \\
\hline History or high risk of Intracranial hemorrhage & $\begin{array}{l}\text { Dabigatran } \\
\text { Rivaroxaban } \\
\text { Apixaban } \\
\text { Edoxaban }\end{array}$ \\
\hline $\begin{array}{l}\text { Stroke or systemic embolism while on } \\
\text { Vitamin K antagonists }\end{array}$ & $\begin{array}{l}\text { Dabigatran } 150 \text { mg BID } \\
\text { Apixaban }\end{array}$ \\
\hline $\begin{array}{l}\text { Renal function impairment } \\
\text { eGFR }<15 \mathrm{~mL} / \mathrm{min} / 1.73 \mathrm{~m}^{2} \\
\text { eGFR } 15-30 \mathrm{~mL} / \mathrm{min} / 1.73 \mathrm{~m}^{2} \\
\text { eGFR } 30-50 \mathrm{~mL} / \mathrm{min} / 1.73 \mathrm{~m}^{2}\end{array}$ & $\begin{array}{l}\text { Vitamin K antagonists } \\
\text { Rivaroxaban } 15 \mathrm{mg} \text { OD Apixaban } 2.5 \mathrm{mg} \text { BID Edoxaban } 30 \mathrm{mg} \text { OD } \\
\text { Dabigatran } 110 \mathrm{mg} \text { BID* Rivaroxaban } 15 \mathrm{mg} \text { OD Apixaban } \\
\text { Edoxaban } 30 \mathrm{mg} \text { OD }\end{array}$ \\
\hline HAS-BLED score $\geq 3$ & $\begin{array}{l}\text { Dabigatran } 110 \mathrm{mg} \text { BID } \\
\text { Apixaban } \\
\text { Edoxaban } 30 \mathrm{mg} \text { OD }\end{array}$ \\
\hline Elderly $>80$ years & $\begin{array}{l}\text { Dabigatran } 110 \mathrm{mg} \mathrm{BID} * * \\
\text { Rivarixaban } \\
\text { Apixaban }\end{array}$ \\
\hline Nasogastric tube due to dysphagia & Rivaroxaban \\
\hline Need for a reversal agent & Dabigatran \\
\hline
\end{tabular}

Fig. 1. A practical algorithm for the dosing

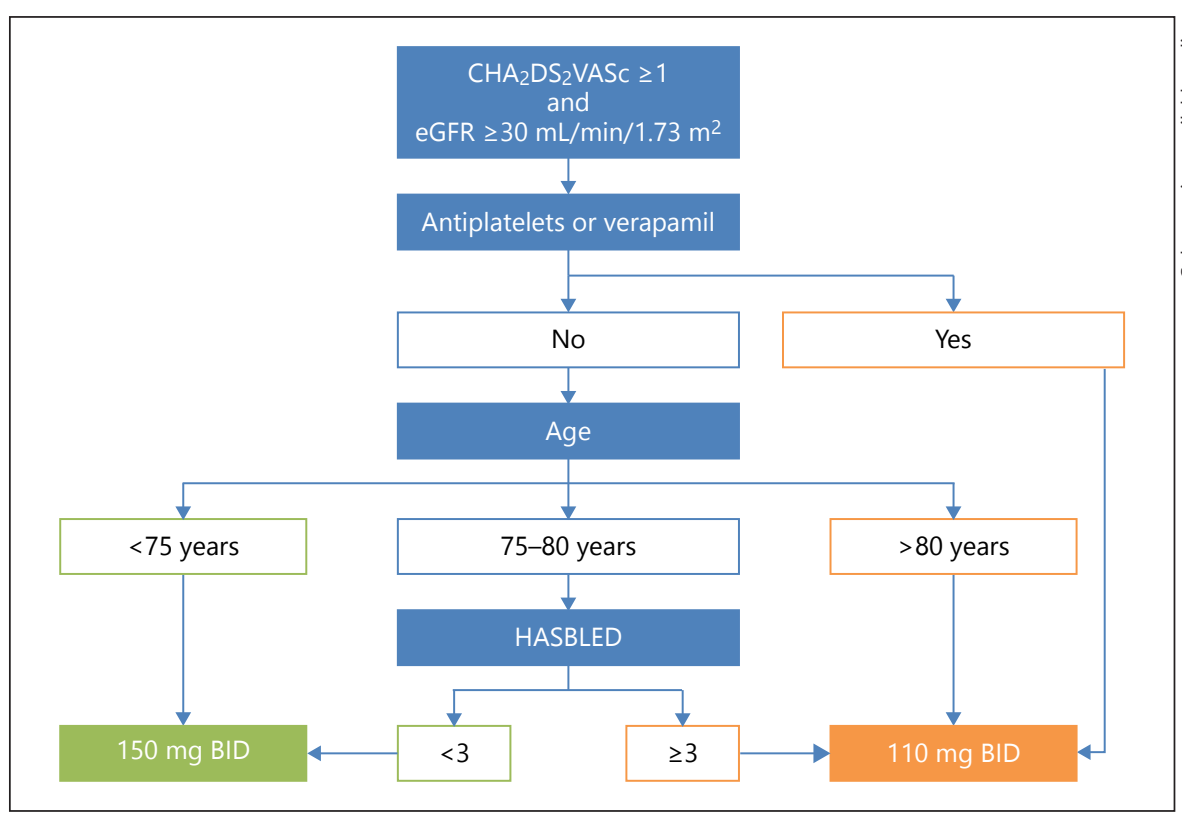
choice of dabigatran. 
the choice may be further guided by the risk of bleeding as defined by the HASBLED score; patients with a HASBLED score lower than 3 should receive $150 \mathrm{mg}$ BID, while those with a HASBLED score of 3 or higher may be treated with $110 \mathrm{mg}$ BID. This approach is outlined in Figure 1.

The standard doses for rivaroxaban are $20 \mathrm{mg} O D$ and $5 \mathrm{mg}$ apixaban BID. In ROCKET-AF and ARISTOTLE, the reduced doses of rivaroxaban (15 $\mathrm{mg} O D)$ and apixaban (2.5 mg BID) were tested only in patients with reduced eGFR and therefore those doses are not tested for efficacy in patients with increased bleeding risk but normal renal function. Consequently, the standard doses should be used. Rivaroxaban $15 \mathrm{mg}$ OD is suitable for patients with eGFR $15-50 \mathrm{~mL} / \mathrm{min} / 1.73 \mathrm{~m}^{2}$ if renal function is normal, but if there is co-existence of factors such as older age, use of antiplatelet drugs, or use of clarithromycin, the reduced dose may be considered [19]. For apixaban, the reduced dose of $2.5 \mathrm{mg}$ BID is recommended if 2 of the following 3 factors coexist: age $>80$ years, creatinine $>1.5 \mathrm{mg} / \mathrm{dL}$, and weight $<60 \mathrm{~kg}$. However, although in such cases eGFR is usually expected to be $<50 \mathrm{~mL} / \mathrm{min} / 1.73 \mathrm{~m}^{2}$, it is advisable to also calculate GFR. For example, an 81-year-old male patient weighing $58 \mathrm{~kg}$ with creatinine $0.6 \mathrm{mg} / \mathrm{dL}$ has an estimated eGFR of $79 \mathrm{~mL} / \mathrm{min} / 1.73 \mathrm{~m}^{2}$ and should not be denied the protective dose of the standard dose of apixaban.

Finally, the standard dose for edoxaban is $60 \mathrm{mg}$ OD. The reduced dose of $30 \mathrm{mg}$ OD is recommended if at least 1 of the following 3 factors is present: eGFR $15-50 \mathrm{~mL} /$ $\min / 1.73 \mathrm{~m}^{2}$, weight $<60 \mathrm{~kg}$, concomitant use of cyclosporine, dronedarone, erythromycin, or ketoconazole.

\section{Conflict of Interest}

D.F. received consultation fees from Boehringer Ingelheim and Daiichi-Sankyo. P.D. received consultation fees from Boehringer Ingelheim. G.G. received consultation fees from Bayer, Boehringer-Ingelheim and Pfizer. G.G. received consultation fees, research grants, and/or speaker honoraria from Bayer, Boehringer Ingelheim and Pfizer. A.P. received consultation fees and/or speaker honoraria from Bayer and Boehringer Ingelheim. G.T. received consultation fees from Bayer and Boehringer Ingelheim. J.P. received consultation fees and/or speaker honoraria from Bayer and Boehringer Ingelheim.

\section{Funding Sources}

The authors have no funding to declare.

\section{References}

1 Connolly SJ, Ezekowitz MD, Yusuf S, Eikelboom J, Oldgren J, Parekh A, Pogue J, Reilly PA, Themeles E, Varrone J, Wang S, Alings M, Xavier D, Zhu J, Diaz R, Lewis BS, Darius $\mathrm{H}$, Diener HC, Joyner CD, Wallentin L; RE-LY Steering Committee and Investigators: Dabigatran versus warfarin in patients with atrial fibrillation. N Engl J Med 2009;361: 1139-1151.

2 Lip GY, Clemens A, Noack H, Ferreira J, Connolly SJ, Yusuf S: Patient outcomes using the European label for dabigatran. A post-hoc analysis from the RE-LY database. Thromb Haemost 2014;111:933-942.

3 Granger CB, Alexander JH, McMurray JJ, Lopes RD, Hylek EM, Hanna M, Al-Khalidi HR, Ansell J, Atar D, Avezum A, Bahit MC, Diaz R, Easton JD, Ezekowitz JA, Flaker G, Garcia D, Geraldes M, Gersh BJ, Golitsyn S, Goto S, Hermosillo AG, Hohnloser SH, Horowitz J, Mohan P, Jansky P, Lewis BS, Lopez-Sendon JL, Pais $P$, Parkhomenko A, Verheugt FW, Zhu J, Wallentin L; ARISTOTLE Committees and Investigators: Apixaban versus warfarin in patients with atrial fibrillation. N Engl J Med 2011;365:981-992.

4 Patel MR, Mahaffey KW, Garg J, Pan G, Singer DE, Hacke W, Breithardt G, Halperin
JL, Hankey GJ, Piccini JP, Becker RC, Nessel CC, Paolini JF, Berkowitz SD, Fox KA, Califf RM; ROCKET AF Investigators: Rivaroxaban versus warfarin in nonvalvular atrial fibrillation. N Engl J Med 2011;365:883891.

5 Giugliano RP, RuffCT, Braunwald E, Murphy SA, Wiviott SD, Halperin JL, Waldo AL, Ezekowitz MD, Weitz JI, Špinar J, Ruzyllo W, Ruda M, Koretsune Y, Betcher J, Shi M, Grip LT, Patel SP, Patel I, Hanyok JJ, Mercuri M, Antman EM; ENGAGE AF-TIMI 48 Investigators: Edoxaban versus warfarin in patients with atrial fibrillation. N Engl J Med 2013;369: 2093-2104.

6 Kirchhof P, Benussi S, Kotecha D, Ahlsson A, Atar D, Casadei B, Castella M, Diener HC, Heidbuchel H, Hendriks J, Hindricks G, Manolis AS, Oldgren J, Popescu BA, Schotten U, Van Putte B, Vardas P; ESC Scientific Document Group: 2016 ESC Guidelines for the management of atrial fibrillation developed in collaboration with EACTS. Eur Heart J 2016; 37:2893-2962.

7 Huisman MV, Lip GY, Diener HC, Brueckmann M, van Ryn J, Clemens A: Dabigatran etexilate for stroke prevention in patients with atrial fibrillation: resolving uncertainties in routine practice. Thromb Haemost 2012;107: 838-847.

8 Potpara TS, Lip GY: Oral anticoagulant therapy in atrial fibrillation patients at high stroke and bleeding risk. Prog Cardiovasc Dis 2015; 58:177-194.

9 Shields AM, Lip GY: Choosing the right drug to fit the patient when selecting oral anticoagulation for stroke prevention in atrial fibrillation. J Intern Med 2015;278:1-18.

10 Lip GYH, Lane DA: Matching the NOAC to the patient: remember the modifiable bleeding risk factors. J Am Coll Cardiol 2015;66: 2282-2284.

11 Sherwood MW, Nessel CC, Hellkamp AS, Mahaffey KW, Piccini JP, Suh EY, Becker RC, Singer DE, Halperin JL, Hankey GJ, Berkowitz SD, Fox KAA, Patel MR: Gastrointestinal bleeding in patients with atrial fibrillation treated with rivaroxaban or warfarin: ROCKET AF trial. J Am Coll Cardiol 2015;66:2271-2281.

12 Pollack CV Jr, Reilly PA, Eikelboom J, Glund S, Verhamme P, Bernstein RA, Dubiel R, Huisman MV, Hylek EM, Kamphuisen PW, Kreuzer J, Levy JH, Sellke FW, Stangier J, Steiner T, Wang B, Kam CW, Weitz JI: Idarucizumab for dabigatran reversal. $\mathrm{N}$ Engl J Med 2015;373:511-520.
Direct Oral Anticoagulants in Nonvalvular Atrial Fibrillation 
13 Connolly SJ, Milling TJ Jr, Eikelboom JW, Gibson CM, Curnutte JT, Gold A, Bronson MD, Lu G, Conley PB, Verhamme P, Schmidt J, Middeldorp S, Cohen AT, Beyer-Westendorf J, Albaladejo P, Lopez-Sendon J, Goodman S, Leeds J, Wiens BL, Siegal DM, Zotova E, Meeks B, Nakamya J, Lim WT, Crowther M; ANNEXA-4 Investigators: Andexanet alfa for acute major bleeding associated with factor Xa inhibitors. N Engl J Med 2016;375: 1131-1141.

14 Bai Y, Deng H, Shantsila A, Lip GY: Rivaroxaban versus dabigatran or warfarin in realworld studies of stroke prevention in atrial fibrillation: systematic review and meta-analysis. Stroke 2017;48:970-976.
15 Larsen TB, Skjøth F, Nielsen PB, Kjældgaard JN, Lip GY: Comparative effectiveness and safety of non-vitamin $\mathrm{K}$ antagonist oral anticoagulants and warfarin in patients with atrial fibrillation: propensity weighted nationwide cohort study. BMJ 2016;353:i3189.

16 Graham DJ, Reichman ME, Wernecke M, Hsueh YH, Izem R, Southworth MR, Wei Y, Liao J, Goulding MR, Mott K, Chillarige Y, MaCurdy TE, Worrall C, Kelman JA: Stroke, bleeding, and mortality risks in elderly medicare beneficiaries treated with dabigatran or rivaroxaban for nonvalvular atrial fibrillation. JAMA Intern Med 2016;176:1662-1671.

17 Farmakis D, Parissis J, Filippatos G: Insights into onco-cardiology: atrial fibrillation in cancer. J Am Coll Cardiol 2014;63:945-953.
18 Steinberg BA, Shrader P, Thomas L, Ansell J, Fonarow GC, Gersh BJ, Kowey PR, Mahaffey KW, Naccarelli G, Reiffel J, Singer DE, Peterson ED, Piccini JP; ORBIT-AF Investigators and Patients: Off-label dosing of non-vitamin $\mathrm{K}$ antagonist oral anticoagulants and adverse outcomes: the ORBIT-AF II registry. J Am Coll Cardiol 2016;68:25972604.

19 Heidbuchel H, Verhamme P, Alings M, Antz M, Diener HC, Hacke W, Oldgren J, Sinnaeve P, Camm AJ, Kirchhof P: Updated European Heart Rhythm Association Practical Guide on the use of non-vitamin $\mathrm{K}$ antagonist anticoagulants in patients with non-valvular atrial fibrillation. Europace 2015;17:1467-1507. 